\title{
Subjectivity for Shift-work of Nursing Students
}

\author{
Sunyoung Jang \\ Department of Nursing, Hanseo University, 46 Hanseol Ro, Haemi-myun, Seosan-si, \\ Chungcheongnam-do, 369-709, Korea \\ sjang@hanseo.ac.kr
}

\begin{abstract}
The purpose of this study is to identify the subjective opinions that nursing students have about shift work and define the characteristics by type. $Q$ methodology was used to determine the subjectivity of nursing students' shift work. A total of 17 students from the A Department of Nursing were selected and asked 38 questions about shift work. Collected data were analyzed using the QUANL PC program. As a result, the perception of shift work was classified into three categories: "reversible side effects recognition", "non-recoverable side effects worried", and "pros and cons considered." It is expected that this will help to identify nurses' perceptions of shift work and to develop strategies for future workforce management.
\end{abstract}

Keywords: Shift work, Nursing students, Subjectivizes, Q-methodology, Nurses

\section{Introduction}

\subsection{Necessity of study}

The hospital needs to provide services 24 hours so nurses in wards, intensive care units, and emergency departments usually work three shifts a day. Shift work cycles vary from two to three days, one week, or several weeks [1]. Nowadays, the shift work system is introduced in various occupations to provide convenience to customers. However, shifting parties work at times that do not match their physical rhythms, which can cause physical and psychological side effects [2][3]. In recent years, the rights of patients have become important in society, and expectations for the quality of nursing services for patients have been increasing. Thus, the physical and mental stress of nurses is also increasing. But because of the lack of nursing staff in the hospital, nurses are under stress due to overload. [4]The health of nurses is very important because it can affect patient safety [5].

Sleep time for shift workers is irregular. This leads to poor quality sleep, which leads to unstable biorhythms [6][7]. In the long run, shift workers are more tired than those who are not, which increases the risk of accidents. These sleep disorders and fatigue during shifts can increase the likelihood of medical accidents by making it difficult for patients to make mistakes, malfunctioning medical devices, and understanding patient status [8][9]. It also can be a barrier to shift workers living a healthy life [7].

The purpose of this study is to understand the subjectivity of shift work from the perspective of nursing students. The aim is to relieve the negative perceptions they have of

Article history:

Received (July 27, 2019), Review Result (September 12, 2019), Accepted (November 28, 2019) 
shift work and to provide the basic data necessary to develop workforce management programs for each type.

\subsection{Purpose of study}

This study uses Q methodology to collect subjectivity and classify subjectivizes of nursing students' shift work and define each type. The data collected will be used as a training resource for students who will work shifts in the future. The purpose of this study is as follows.

1) Type the subjective opinions that nursing students have about shift work.

2) Define perceptions of shift work by type, then analyze their characteristics.

\section{Method of study}

\subsection{Design of the study}

To achieve the purpose of the study, we first reviewed the literature, media data, and research results on shift work. And we collected opinions about shift work from students who have already experienced shift work.

\section{2. $Q$ population and $Q$ sample selection}

First of all, to derive the Q-population, the interviews and questionnaires were conducted for students in the nursing department. Based on domestic and international research data on shift work, a total of 200 questions in three areas were first extracted. And we proceeded to select this to 100 again. Finally, a total of 38 final questions were selected by expert review.

\subsection{P-sample selection method}

Q-methodology is a research method that can identify differences according to an individual's unique experience. This method was conducted in consideration of the "small sample doctrine" that the larger the P-sample, the more biased the opinions are in a particular area and the results may be different [10]. Among the students in the department, 17 participants were selected who indicated their willingness to participate.

\subsection{Q-Classification and data analysis methods}

Q-classification is the process of defining opinions on shift work for each individual by classifying them into forced normal distribution according to the answers of participants selected as P-sample [10]. Data were collected using a Q-card from 17 students in the A Department of Nursing. The average time spent per study respondent was 30 to 45 minutes. The distribution of Q-samples was classified by classifying the respondents' responses to Qsamples from strong positives to strong negatives. Thereafter, interviews were made with attendees regarding answers categorized at both ends. As the Q-analysis factor, Principle Component Factor Analysis (varimax) method was used. Classification of types was based on Eigenvalue 1.0 or higher. The results and variances calculated by varying the number of factors were considered. Collected data were scored on a scale of 1 to 10, centered on cards forcibly distributed in the Q-sample distribution table. The assigned conversion scores were coded in Q-sample number order and processed by Principle Component Factor Analysis (varimax) by the QUANL PC Program. 


\subsection{Ethical consideration for research subjects}

Before starting the study, participants were informed that they could discontinue at any time at their discretion. All information collected for the rights and privacy of attendees was coded and stored anonymously.

\section{Result of a study}

\subsection{Subjectivity and type-specific characteristics of shift work}

To divide the nursing students' perceptions of shift work by type, the answers to Qsamples were first collected and divided into three types. In the Q-method, each type finds a person with a high "Factor weight" and identifies them as an "ideal person" representing that type.

The classification was based on the case where the standard score was 1.00 or higher among the responses to the collected Q-samples. Persons with a "Factor weight" of 1.00 or greater were counted as seven for Type 1 , four for Type 2, and six for Type 3 .

\subsection{Type-specific characteristics for shift work}

The types of perceptions of nursing students about shift work classified through the above process are as follows.

- Reversible Side Effects Recognition type: A total of seven respondents were classified as the first type. Questions that strongly indicate a positive affirmation by this type of subject include: Shift work is difficult to get a good night's sleep because of shift work, which causes sleep disorders and chronic fatigue $(Z=2.03)$, The physical rhythm is broken because of shift work $(Z=1.95)$ Shift work is the cause of chronic fatigue $(Z=1.69)$ [Table 1]. The 11th (1.0292) had the highest "Factor weight" in Type I. The questions he most agreed to were 2, 1, and 27. Questions that strongly indicate negative intentions of the first type of subject are as follows. Drug abuse increases due to shifting work $(Z=-1.82)$, Shift workers have less sense of belonging to the organization $(Z=-1.72)$, and Shift work affects smoking $(Z=-1.37)$ [Table 1]. The 11th (1.0292) had the highest "Factor weight" in Type I. The questions he most agreed to were 2, 1, and 27. Participants with the lowest "Factor weight" in Type 1 were No. 6 (0.4465). The strongest and most negatively answered questions were 31, 37, and 24. Respondents of the first type answered that shift work can cause some side effects, but they thought they were recoverable. Nurses need to work shifts to care for patients, which causes fatigue and stress from sleep disorders. However, it appears that they do not significantly affect the mentality or habits of nurses. New nurses may find that shifting early may feel burdensome but think they will adapt over time. Therefore, the first type was named "reversible side effect recognition type".

- Non-recoverable side effect worry type: A total of four respondents were classified as the second type. Questions that strongly indicate a positive affirmation by this type of subject include: The physical rhythm is broken because of shift work $(\mathrm{Z}=2.06)$ It is difficult to get a good night's sleep because of shift work, which causes sleep disorders and chronic fatigue $(\mathrm{Z}=1.75)$, Reproductive function is impaired by shift work $(\mathrm{Z}=1.56)$ [Table 1]. The 5th (3.2926) had the highest "Factor weight" in Type 2. The questions he most agreed to were 1, 2 , and 28. Questions that strongly indicate negative intentions of the second type of subject are as follows. Shift work naturally leads to an extension of work $(Z=-1.81)$, Fixed shift work can stabilize life rhythms and return work performance to normal $(Z=-1.56)$, Shift work 
cycles affect turnover $(\mathrm{Z}=-1.34)$ [Table 1] Participants with the lowest "Factor weight" in Type 2 were No. 4 (0.2612). The strongest and most negatively answered questions were 18 , 36, and 20. Participants in the second category considered shift work to be the cause of physical, psychological, and mental side effects. They also concluded that they could not recover even after returning to normal life patterns. The shift workers felt that the side effects would be worse because they were in an unsuitable environment to care for their health. Accordingly, the second type was named "non-recoverable side effect worry type".

- Pros and cons consideration type: A total of six respondents were classified as the third type. Questions that strongly indicate a positive affirmation by this type of subject include: New nurses do not sleep deeply while adjusting to shifting work $(\mathrm{Z}=1.78)$, The physical rhythm is broken because of shift work $(Z=1.73)$, Employees who are satisfied with their work shift can maintain their mental and physical health $(\mathrm{Z}=1.55)$ [Table 1]. The 15th (1.5101) had the highest "Factor weight" in Type 3 . The questions they most agreed to were 8,1 , and 34. Questions that strongly indicate negative intentions of the second type of subject are as follows: Shift work affects smoking $(\mathrm{Z}=-1.93)$, Drug abuse increases due to shift work $(\mathrm{Z}=-$ 1.83), Shift work causes family discord $(Z=-1.83)$ [Table 1]. Participants with the lowest "Factor weight" in Type 3 were No. 9 (03143). The strongest and most negatively answered questions were 24, 31, and 30. Participants in the third category thought that shifts could have side effects, but could be relieved according to their will and circumstances. They felt that if they were satisfied with the shift, they would be able to stay healthy and provide opportunities for self-achievement. Accordingly, the third type is called the "pros and cons consideration type."

Table 1. Representative questions on shift work and $\mathrm{Z}$-score $(\mathrm{N}=17)$

\begin{tabular}{|c|c|c|c|c|}
\hline Factor & No & Description & Mean (SD) & $\begin{array}{c}\text { Z- } \\
\text { score }\end{array}$ \\
\hline \multirow{6}{*}{$\begin{array}{l}\text { Factor } 1 \\
(\mathrm{~N}=7)\end{array}$} & 2 & $\begin{array}{l}\text { It is difficult to get a good night's sleep because of shift } \\
\text { work, which causes sleep disorders and chronic fatigue. }\end{array}$ & $8.71(0.756)$ & 2.03 \\
\hline & 1 & The physical rhythm is broken because of shift work. & $8.86(0.9)$ & 1.95 \\
\hline & 27 & Shift work is the cause of chronic fatigue. & $8.43(1.512)$ & 1.69 \\
\hline & 31 & Drug abuse increases due to shifting work. & $2.57(1.718)$ & -1.82 \\
\hline & 37 & $\begin{array}{l}\text { Shift workers have less sense of belonging to the } \\
\text { organization. }\end{array}$ & $2.71(1.604)$ & -1.72 \\
\hline & 24 & Shift work affects smoking. & $2.86(1.345)$ & -1.37 \\
\hline \multirow{6}{*}{$\begin{array}{c}\text { Factor } 2 \\
(\mathrm{~N}=4)\end{array}$} & 1 & The physical rhythm is broken because of shift work. & $8.75(0.957)$ & 2.06 \\
\hline & 2 & $\begin{array}{l}\text { It is difficult to get a good night's sleep because of shift } \\
\text { work, which causes sleep disorders and chronic fatigue. }\end{array}$ & $8.75(0.957)$ & 1.75 \\
\hline & 28 & Reproductive function is impaired by shift work. & $7.50(1.291)$ & 1.56 \\
\hline & 18 & Shift work naturally leads to the extension of work. & $4.25(3.403)$ & -1.81 \\
\hline & 36 & $\begin{array}{l}\text { Fixed shift work can stabilize life rhythms and return } \\
\text { work performance to normal. }\end{array}$ & $4.00(3.599)$ & -1.56 \\
\hline & 20 & Shift work cycles affect turnover. & $4.25(2.630)$ & -1.34 \\
\hline \multirow{6}{*}{$\begin{array}{l}\text { Factor } 3 \\
(\mathrm{~N}=6)\end{array}$} & 8 & $\begin{array}{l}\text { New nurses do not sleep deeply while adjusting to } \\
\text { shifting work. }\end{array}$ & $7.83(1.722)$ & 1.78 \\
\hline & 1 & The physical rhythm is broken because of shift work. & $8.00(0.894)$ & 1.73 \\
\hline & 34 & $\begin{array}{l}\text { Employees who are satisfied with their work shift can } \\
\text { maintain their mental and physical health. }\end{array}$ & $7.00(2.757)$ & 1.55 \\
\hline & 24 & $\begin{array}{l}\text { Shift work affects smoking. } \\
\end{array}$ & $2.67(1.751)$ & -1.93 \\
\hline & 31 & Drug abuse increases due to shifting work. & $3.17(1.169)$ & -1.83 \\
\hline & 30 & Shift work causes family discord. & $2.83(0.753)$ & -1.83 \\
\hline
\end{tabular}




\section{Discussion}

According to the results of this study, the subjectivizes of nursing students' shift work are classified into three categories. The first type is the "reversible side effect recognition type", the second type is the "non-recoverable side effect worry type", and the third type is the "pros and cons consideration type" and the characteristics of each type are as follows.

The first type identified in this study is "reversible side effects recognition". Attendees of this type believe that shifts are essential because the job of a nurse must take care of patients 24 hours a day. They think that shifts can cause side effects, but they can be restored depending on the lifestyle. They think it's hard to work shifts but they can stand it.

The second type is "non-recoverable side effects worry". Attendees of this type believe that the side effects of shift work cannot be recovered. If possible, they also tend to hope for a full-time job or another job that does not work shifts. Above all, they put their health first, and they have a vague fear of this even though they had not yet started their shift work.

The third type is "pros and cons consideration". Attendees of this type were found to think that shifts could be a source of side effects, but that they could take advantage of them. They do their best to actively manage their health and adapt to shift work. So if there is policy support for nurses working in shifts, we think that the rate at which nurses leave because of shifts will be reduced.

In this study, we searched for subjective opinions that nursing students have about shift work and classified them into three types by their characteristics and analyzed them. This may help to develop a workforce management program for shift nurses, which has recently gained increasing attention.

However, it was not easy to generalize the results of this study because a questionnaire was conducted for one university and the participants were selected by excluding factors affecting the perception of shift work. Therefore, further research is needed to construct a Q-sample with various backgrounds and further verify the classified types.

\section{Conclusion}

This study collected and analyzed subjective perceptions of nursing students' shift work. In addition, based on the research results, it was intended to be used as basic data for finding ways to activate shift work. Through research, perceptions of shift work were classified into three types. These are "reversible side effects recognition", "non-recoverable side effects worry" and "pros and cons consideration".

This study types the subjectivity of nursing students' shift work. These classified types served as the basis for introducing supportive policies to overcome the adverse effects of future shift work. Based on the results of this study, it is expected that the workforce management program for nurses working in the future will be developed. In addition, to generalize the results of this study, it is suggested to select additional samples considering various factors for further study. 


\section{References}

[1] H. J. Ko, M. J. Y. Kim, Y. S. Kwon, C. N. Kim, K. M. Park, J. S. Park, Y. S. Park, C. J. Park, Y. H. Shin, L. H. Lee, B. S. Lee, and E. J. Lee, "The fatigue experience of shift work nurses," Journal of Korean Public Health Nursing, vol.18, no.1, pp.103-118, (2004)

[2] N. Y. Park, H. K. Yang, H. L. Kim, and Y. C. Cho, "Relationship between shift work, and sleep problems and fatigue symptoms of nurses for general hospitals," Korean Journal of Occupational Health Nursing, vol.16, pp.37-47, (2007)

[3] H. Y. So, H. S. Yoon, and Y. C. Cho, "Effects of quality of sleep and related factors for fatigue symptoms of nurses in a university hospital," Journal of Korean Academy of Adult Nursing, vol.20, pp.513-525, (2008)

[4] S. S. Kim, J. S. Park, and Y. S. Roh, "The relationships of individual characteristics, perceived health status, body image, and health-promoting behavior," Journal of Korean Academy of Adult Nursing, vol.17, pp.88-99, (2005)

[5] P. A. Ratner and R. Sawatzky, "Health status, preventive behavior, and risk factors among female nurses," Health Reports, vol.20, no.3, pp.1-9, (2009)

[6] S. F. Niu, M. H. Chung, D. H. Chen, D. Hegney, A. O’Brien and K. R. Chou, "The Effect of Shift Rotation on Employee Cortisol Profile, Sleep Quality, Fatigue, and Attention Level: A Systematic Review," Journal of Nursing Research, vol.19, no.1, pp.68-81, (2011) DOI: 10.1097/JNR.0b013e31820c1879

[7] J. Shen, L. C. Botly, S. A. Chung, A. L. Gibbs, S. Sabanadzovic and C. M. Shapiro, "Fatigue and shift work," Journal of Sleep Research, vol.15, pp.1-5, (2006)

[8] O. Takashi, K. Amm, S.Tomofumi, I. Toshihiro, U. Makoto, M. Masumi, and N. Sadahiko, "Night-Shift Work Related Problems in Young Female Nurses in Japan,” Journal of Occupational Health, vol.43, pp.150156, (2001)

[9] S. D. Yuan, M. C. Chou, C. J. Chen, Y. J. Lin, M. C. Chen and H. H. Liu, "Influences of shift work on fatigue among nurses," Journal of Nursing Management, vol.19, pp.339-345, (2011) DOI: 0.1111/j.13652834.2010.01173.x

[10] S. M. Whang, S. W. You, J. Y. Kim, and R. G. Kim, "Consumer Types and Cultural Consumption Characteristics of Korean Society: Who Spends for What Reasons?” Journal of Human Subjectivity, vol.13, pp.25-39, (2006) 